\title{
Long-Term Treatment With Morphine Increases the D-Serine Content in the Rat Brain by Regulating the mRNA and Protein Expressions of Serine Racemase and D-Amino Acid Oxidase
}

\author{
Masanobu Yoshikawa ${ }^{1}$, Takashi Shinomiya ${ }^{2}$, Naoko Takayasu ${ }^{3}$, Hideo Tsukamoto ${ }^{3}$, Mitsuru Kawaguchi ${ }^{2}$, \\ Hiroyuki Kobayashi ${ }^{1}$, Tetsuo $\mathrm{Oka}^{1}$, and Atsushi Hashimoto ${ }^{1, *}$ \\ ${ }^{I}$ Department of Clinical Pharmacology, ${ }^{3}$ Laboratory for Molecular Science Research, Tokai University School of Medicine, \\ Isehara, Kanagawa 259-1143, Japan \\ ${ }^{2}$ Department of Pharmacology, Tokyo Dental College, 1-2-2 Masago, Mihama-ku, Chiba 261-8502, Japan
}

Received January 30, 2008; Accepted May 12, 2008

\begin{abstract}
Recent studies indicate that an endogenous co-agonist for an $\mathrm{N}$-methyl-D-aspartate (NMDA) receptor-related glycine site, D-serine, is synthesized by serine racemase and is metabolized by D-amino acid oxidase (DAO) and that acute treatment with morphine augments the gene expression of serine racemase and DAO in rat brain. To further elucidate the mechanism underlying the activation of NMDA receptors following chronic opioid administration, we have evaluated the effects of the chronic administration of morphine on the mRNA and protein expressions of serine racemase and DAO and on the contents of D-serine in several areas of the rat brain. Repeated administration of morphine for 30 days produced a significant augmentation of both the mRNA and protein expressions of serine racemase in all the brain regions, whereas no significant change in the protein expression of DAO was observed in all the brain regions. Furthermore, the chronic administration caused a slight but significant elevation in the concentration of D-serine in the cortex, striatum, and hippocampus. These results indicate the elevated D-serine level following the chronic morphine treatment could at least in part be involved in the activation of NMDA receptors via the glycine site.
\end{abstract}

Keywords: D-serine, serine racemase, D-amino acid oxidase, morphine, $\mathrm{N}$-methyl-D-aspartate receptor

\section{Introduction}

A large body of evidence has demonstrated that Dserine acts as an endogenous and obligatory co-agonist for the glycine site of the $N$-methyl-D-aspartate (NMDA) receptors in the mammalian brain. D-Serine is confined to the forebrain where the NMDA receptors are enriched $(1-3)$. In vivo microdialysis studies have also shown that the extracellular concentration of D-serine parallels or is higher than that of glycine in the prefrontal cortex and striatum, respectively (4). Serine racemase, which converts L-serine to D-serine, has recently been cloned from the mammalian brain $(5,6)$. Several lines of

*Corresponding author. hashimot@is.icc.u-tokai.ac.jp Published online in J-STAGE on July 5, 2008 (in advance) doi: $10.1254 /$ jphs.08030FP evidence have indicated that the regional profile of serine racemase closely resembles those of the endogenous D-serine and NMDA receptors with the highest level in the forebrain and the lowest level in the hindbrain $(1,5,7)$. In contrast, D-amino acid oxidase (DAO), which catalyzes the oxidative deamination of neutral D-amino acids, predominantly occurs in the hindbrain $(2,8,9)$. We have recently shown that a moderate dose of MK-801 $(0.4 \mathrm{mg} / \mathrm{kg})$ upregulates the gene expression of serine racemase and DAO in the rat brain, which suggests that there is a link between the gene expression of the D-serine-related enzymes and the blockade of the NMDA receptor $(7,9)$.

Numerous data have demonstrated that there is a link between the NMDA receptor and $\mu$-opioid receptor systems (10). Indeed, repeated morphine administration induces the changes that would directly or indirectly 
produce the activation of NMDA receptors. Chronic morphine exposure, for example, results in the enhanced expression of the NMDAR1 subunit mRNA in the locus coeruleus and the hypothalamic paraventricular nucleus $(11,12)$ and of the NMDAR1 and NMDAR2B proteins in the nucleus accumbens (13). Chronic morphine also produces the reduced expression of glial glutamate transporters in the striatum and thalamus, indicating a resultant elevation of extracellular glutamate concentration (14). In addition, our recent studies have revealed that acute treatment with morphine augments the expression of serine racemase and DAO mRNAs in rat brain, suggesting an interaction between the gene expression of the D-serine-related enzymes and opioid receptor activation (15).

Despite a number of studies indicating that chronic morphine administration leads to the activation of NMDA receptors in the brain $(16-19)$, there are conflicting reports regarding the action of chronic morphine. Chronic morphine treatment, for example, decreases NMDA receptor-mediated responses detected by intracellular recording in slice preparation from nucleus accumbens and the affinity of glycine, the NMDA receptor coagonist, in isolated neurons from nucleus accumbens $(20,21)$. In the present study, to gain further insight into the interaction between the NMDA receptor and opioid receptor systems following chronic morphine administration and the involvement of an endogenous NMDA receptor-glycine site co-agonist, D-serine, in the activation of NMDA receptors, we evaluated the changes in the mRNA and protein expressions of serine racemase and DAO, and the contents of D-serine and L-serine in the rat brain after chronic morphine administration.

\section{Materials and Methods}

\section{Animals}

The present animal experiments were performed in strict accordance with the guidelines of Tokai University and were approved by the Animal Investigation Committee of the University. Male Wistar rats (Clea Japan, Inc., Tokyo) ranging in weight from 160 to $170 \mathrm{~g}$ at the beginning of the experiment were used. The rats were group-housed in laboratory cages and kept in a temperature-controlled room $\left(23 \pm 2^{\circ} \mathrm{C}\right)$ with a 12 -h light/dark cycle (light on: 7:00) with food and water freely available.

\section{Morphine administration}

Chronic morphine treatment was initiated after the acclimation period with the drug administered as follows (doses of morphine in milligrams per kilogram by i.p. administration, AM 10:00 dose / PM 5:00 dose): Day 1 $(5 \mathrm{mg} / \mathrm{kg} / 7.5 \mathrm{mg} / \mathrm{kg})$, Day $2(7.5 \mathrm{mg} / \mathrm{kg} / 10 \mathrm{mg} / \mathrm{kg})$, Day $3(10 \mathrm{mg} / \mathrm{kg} / 12.5 \mathrm{mg} / \mathrm{kg})$, Day $4(12.5 \mathrm{mg} / \mathrm{kg}$ $/ 15 \mathrm{mg} / \mathrm{kg})$, Day $5(15 \mathrm{mg} / \mathrm{kg} / 17.5 \mathrm{mg} / \mathrm{kg})$, and Day $6(17.5 \mathrm{mg} / \mathrm{kg} / 20 \mathrm{mg} / \mathrm{kg})$. After 6 days of acclimation period, as described above, rats were intraperitoneally administered with morphine $(20 \mathrm{mg} / \mathrm{kg})$ twice per day for 24 days. In a control experiment, rats were intraperitoneally administered for 30 days twice daily with saline. Following these treatments, the rats were stunned and decapitated $16 \mathrm{~h}$ after the last administration.

\section{Real time quantitative reverse transcriptase-polymerase chain reaction ( $R T-P C R$ )}

The gene expression of the glyceraldehyde 3phosphate dehydrogenase (GAPDH; GenBank accession number NM_017008), serine racemase (accession number NM_198757) and DAO (accession number NM_053626) was determined by real-time quantitative RT-PCR using a method similar to the one described previously $(7,9)$. Briefly, the cDNA was amplified by real-time PCR using the DyNAmo SYBER green qPCR Kit (Finnzymes, Espoo, Finland) on the DNA Engine Opticon 2 System (Bio-Rad Laboratories, Hercules, CA, USA). The PCR products were separated by an Agilent 2100 Bioanalyzer (Agilent Technologies, Palo Alto, CA, USA) that utilizes chip-based nucleic acid separation technology. Furthermore, the identification of the amplified PCR products of the serine racemase, DAO, and GAPDH cDNAs were determined by dye terminator cycle sequencing.

\section{Western blotting}

A tissue sample was homogenized in 10 volumes of the following buffer: $9.1 \mathrm{mM} \mathrm{NaH} \mathrm{NO}_{4}, 1.7 \mathrm{mM}$ $\mathrm{Na}_{2} \mathrm{HPO}_{4} \quad(\mathrm{pH} 7.4), \quad 150 \mathrm{mM} \quad \mathrm{NaCl}, \quad 0.5 \%$ sodium deoxycholate, $0.1 \%$ sodium dodecyl sulphate (SDS), $1 \mathrm{mM}$ phenylmethylsulfonylfluoride supplemented with one tablet of protease inhibitor mixture (Complete Inhibitor Cocktail Set; Roche Diagnostics, Mannheim, Germany) for $50 \mathrm{ml}$. The homogenate was centrifuged at $16,000 \times g$ for $45 \mathrm{~min}$ at $4^{\circ} \mathrm{C}$. Protein concentration in the supernatant solution was determined using a DC Protein Assay Kit (Bio-Rad Laboratories). Protein samples were solubilized with an equal volume of sample buffer (20 mM Tris-HCl, pH 6.8, 2\% SDS, 5\% 2-mercaptoethanol, $10 \%$ glycerol) for $5 \mathrm{~min}$ at $95^{\circ} \mathrm{C}$ and then subjected to $12.5 \%$ SDS-polyacrylamide gel electrophoresis. Proteins were electrically transferred onto polyvinylidene fluoride membranes (Immobilon P; Nippon Millipore, Tokyo). Membranes were blocked for $1 \mathrm{~h}$ at room temperature with $3 \%$ bovine serum albumin 
in phosphate-buffered saline (PBS) (10 mM phosphate, $\mathrm{pH} 7.4,150 \mathrm{mM} \mathrm{NaCl})$. The membrane was washed in PBS containing $0.05 \%$ Tween-20 (T-PBS) and then incubated overnight at $4{ }^{\circ} \mathrm{C}$ in primary antibody consisting of mouse anti-mouse serine racemase (1:500, Catalog number 612053; Becton Dickinson Bioscience, San Jose, CA, USA), sheep anti-Pig kidney DAO (1:4000, Catalog number 100-601-143; Rockland, Gilbertsville, PA, USA), or mouse anti-mouse GAPDH (1:5000, Catalog number sc-32233; Santa Cruz Biotechnology, Inc., Santa Cruz, CA, USA) in G buffer (PBS containing $0.1 \%$ BSA, $0.1 \%$ gelatin, $0.1 \% \mathrm{NaN}_{3}$, and $1 \mathrm{mM} \mathrm{MgCl}$ ). The membranes were then rinsed in T-PBS and incubated for $1 \mathrm{~h}$ at room temperature with secondary antibody conjugated to horseradish peroxidase anti-mouse antibody (1:5000, Catalog number NA9310V; GE Healthcare Bioscience Japan, Tokyo) or anti-goat antibody (1:10000, Catalog number P0449; DakoCytomation Japan, Kyoto) in T-PBS. Signal detection was carried out using the ECL Plus Western Blotting Detection System (GE Healthcare Bioscience). The Western blot band images were captured using a CCD camera system, Cool Saver (ATTO Corporation, Tokyo). The specific bands were then analyzed for density using a CS Analyzer (ATTO Corporation). GAPDH protein expression was quantified to normalize the amount of protein in each sample.

\section{Measurement of D-serine levels}

The simultaneous determination of the free amino acid enantiomers and non-chiral amino acids in the tissue sample was accomplished using high performance liquid chromatography (HPLC) and fluorometric detection as previously described (1). Briefly, a tissue sample was homogenized in 10 volumes of $5 \%$ trichloroacetic acid after the addition of D-homocysteic acid, and the homogenate was centrifuged at $16,000 \times g$ for $30 \mathrm{~min}$ at $4^{\circ} \mathrm{C}$. The supernatant was washed three times with water-saturated diethyl ether. The aqueous layer was then passed through a Millipore filter (HV, $0.45 \mathrm{~mm}$; Nippon Millipore) and stored at $-80^{\circ} \mathrm{C}$ until derivatization. The resultant sample was derivatized with $N$-tertbutyloxycalbonyl-L-cycteine and $o$-phaldialdehyde for $2 \mathrm{~min}$ at room temperature. The amino acid derivative was immediately applied to the HPLC system.

\section{Statistical analysis}

These results are given as the mean with standard error of the mean (S.E.M.) of the data. Statistical evaluations for measurement of the mRNA, protein, or D-serine levels were carried out by the Mann-Whitney test. A $P$-value $<0.05$ was considered as reaching statistical significance.

\section{Results}

Effect of the chronic administration of morphine on the $m R N A$ expression of serine racemase and DAO in several brain areas

Figure 1A shows data for the levels of serine racemase mRNA $16 \mathrm{~h}$ after the last administration of morphine. After the chronic morphine administration, the expression of serine racemase mRNA significantly increased by $50 \%-165 \%$ in all the brain areas: striatum (65\% increase), hippocampus $(50 \%)$, cortex $(104 \%)$, diencephalon $(81 \%)$, midbrain $(165 \%)$, pons-medulla $(77 \%)$, and cerebellum (97\%). The highest elevation in the expression of serine racemase mRNA was observed in the midbrain. As shown in Fig. 1B, the chronic treatment with morphine produced a slight but significant enhancement in the levels of DAO mRNA in the forebrain regions. The levels increased by $24 \%-102 \%$ in the striatum ( $87 \%$ increase), hippocampus (102\%), and cortex $(24 \%)$. In contrast, no significant change in the expression of DAO mRNA was found in the diencephalon, midbrain, pons-medulla, and cerebellum.
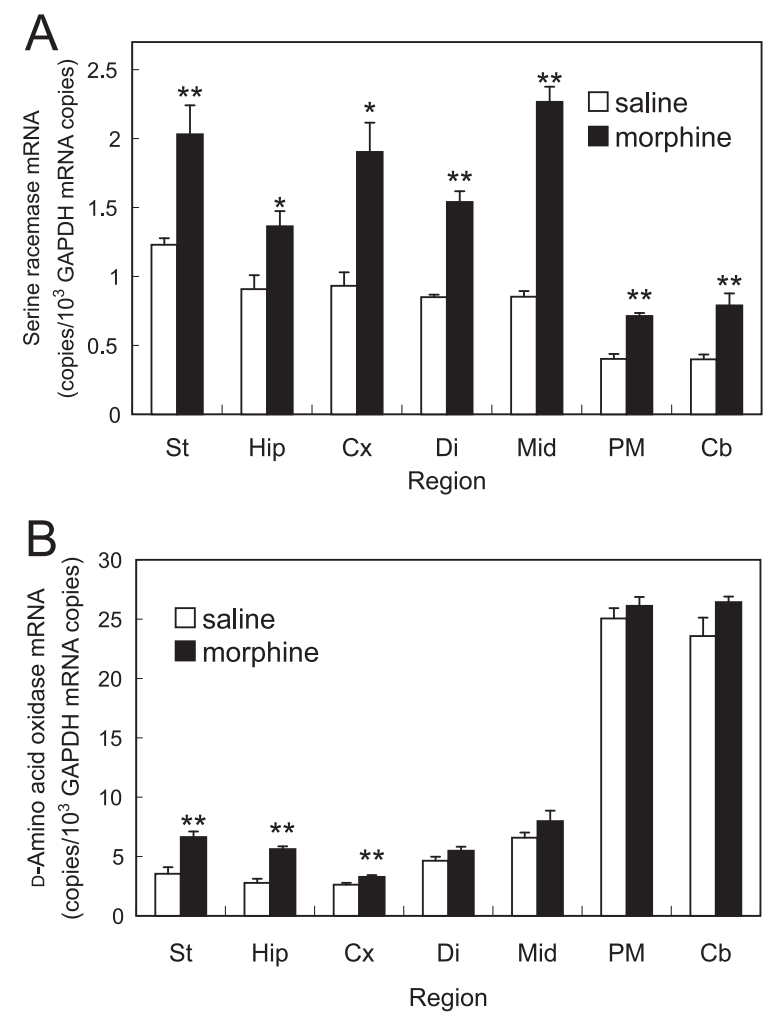

Fig. 1. Effect of chronic administration of morphine on the mRNA expressions of serine racemase (A) and D-amino acid oxidase (B) in several brain areas of rats. Results are each the mean with S.E.M. of data obtained from six rats. ${ }^{*} P<0.05,{ }^{* *} P<0.01$, as compared with the saline-treated group by the Mann-Whitney test. St, striatum; Hip, hippocampus; $\mathrm{Cx}$, cortex; Di, diencephalon; Mid, midbrain; PM, pons-medulla; $\mathrm{Cb}$, cerebellum. 
Protein expression of serine racemase and DAO in several brain areas

We examined the protein levels of serine racemase and DAO in the discrete brain regions of rats following the chronic administration of saline. As shown in Fig. 2A, the protein level of serine racemase was high in the cortex (224\%), striatum (199\%), hippocampus (194\%), followed by the diencephalon (164\%) and midbrain $(130 \%)$ and was low in the pons-medulla $(69 \%)$ and cerebellum expressed as $100 \%$ for the level of the cerebellum. As shown in Fig. 2B, the DAO protein was detected in the pons-medulla $(87 \%)$, midbrain $(12 \%)$, and cerebellum expressed as $100 \%$ for the level of the cerebellum. The DAO protein was not detected in the striatum, hippocampus, cortex, and diencephalon of saline-treated rats. The regional profile of the protein levels of serine racemase and DAO (Fig. 2) was consistent with that of the mRNA levels of the two enzymes (Fig. 1).

Effect of the chronic administration of morphine on the protein expression of serine racemase and DAO in several brain areas

Figure 3 shows data for the levels of serine racemase and DAO $16 \mathrm{~h}$ after the final administration of morphine. The chronic administration of morphine caused a slight but significant elevation in the protein expression of serine racemase in most parts of the brain (Fig. 3A). The levels significantly increased by $16 \%$ $59 \%$ in the striatum (23\% increase), hippocampus $(26 \%)$, cortex $(35 \%)$, diencephalon $(36 \%)$, midbrain $(59 \%)$, pons-medulla (39\%), and cerebellum (16\%). The highest elevation in the protein expression of serine racemase was seen in the midbrain. The augmentation of the protein expression for serine racemase (Fig. 3A) coincides well with that of the mRNA expression for serine racemase (Fig. 1A). Figure 3B shows data for the levels of DAO $16 \mathrm{~h}$ after the final administration of morphine. Following the chronic morphine administration, no significant change in the protein expression of DAO was seen in the midbrain, pons-medulla, and cerebellum. The protein expression of DAO was under the detection limit in the striatum, hippocampus, cortex, and diencephalon following the chronic morphine administration. No significant change in the protein expression of DAO in the midbrain, pons-medulla, and cerebellum (Fig. 3B) corresponds with that in the mRNA expression of DAO in the hindbrain (Fig. 1B).

\section{Effect of the chronic administration of morphine on the} levels of D-serine in several brain areas

As shown in Fig. 4A, the chronic morphine administration produced a slight but significant augmentation
A Serine racemase (Srr)
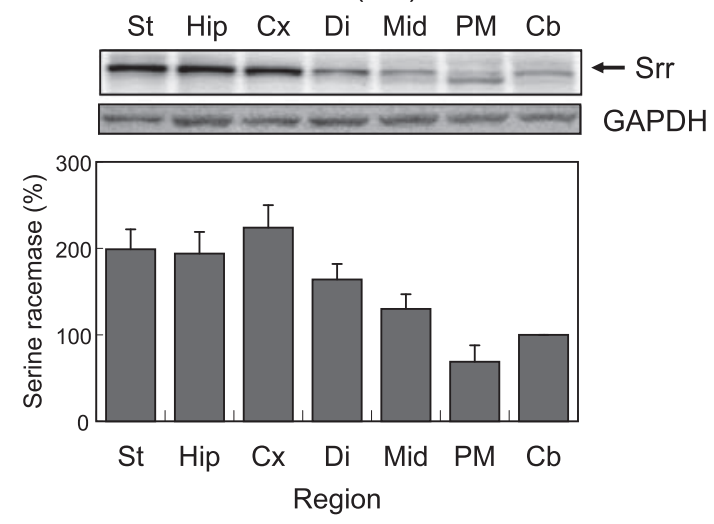

B D-Amino acid oxidase (DAO)
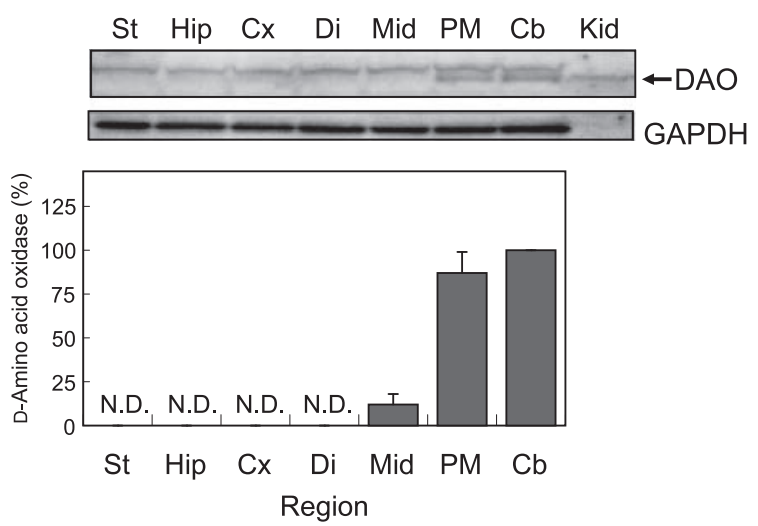

Fig. 2. The protein expressions of serine racemase and D-amino acid oxidase (DAO) in several brain areas of rats. The protein levels of serine racemase or DAO were measured by Western blotting. A $50-\mu \mathrm{g}$ sample of protein extracted from several brain areas and $5 \mu \mathrm{g}$ of kidney were separated by $12.5 \%$ SDS-PAGE. Results are each the mean with S.E.M. of data obtained from six rats. A: The protein expression of serine racemase is expressed as $100 \%$ for the level of the cerebellum. Images of Western blot analysis of serine racemase and GAPDH were performed with the respective specific antibodies using the same extract. Arrow indicates migration of the serine racemase. B: The protein expression of DAO is expressed as $100 \%$ for the level of the cerebellum. Images of Western blot analysis of DAO and GAPDH were performed with the respective specific antibodies using the same extract. Arrow indicates migration of the DAO. St, striatum; Hip, hippocampus; $\mathrm{Cx}$, cortex; Di, diencephalon; Mid, midbrain; PM, pons-medulla; $\mathrm{Cb}$, cerebellum; Kid, kidney; N.D., not detectable.

of the D-serine concentrations in the forebrain areas: striatum ( $9 \%$ increase), hippocampus $(15 \%)$, and cortex (14\%), whereas chronic administration showed no significant effect on the levels of D-serine in the diencephalon, midbrain, pons-medulla, and cerebellum. In addition, chronic treatment caused a slight but significant enhancement of the L-serine concentrations in all the brain areas except for the pons-medulla (Fig. 4B). 
A
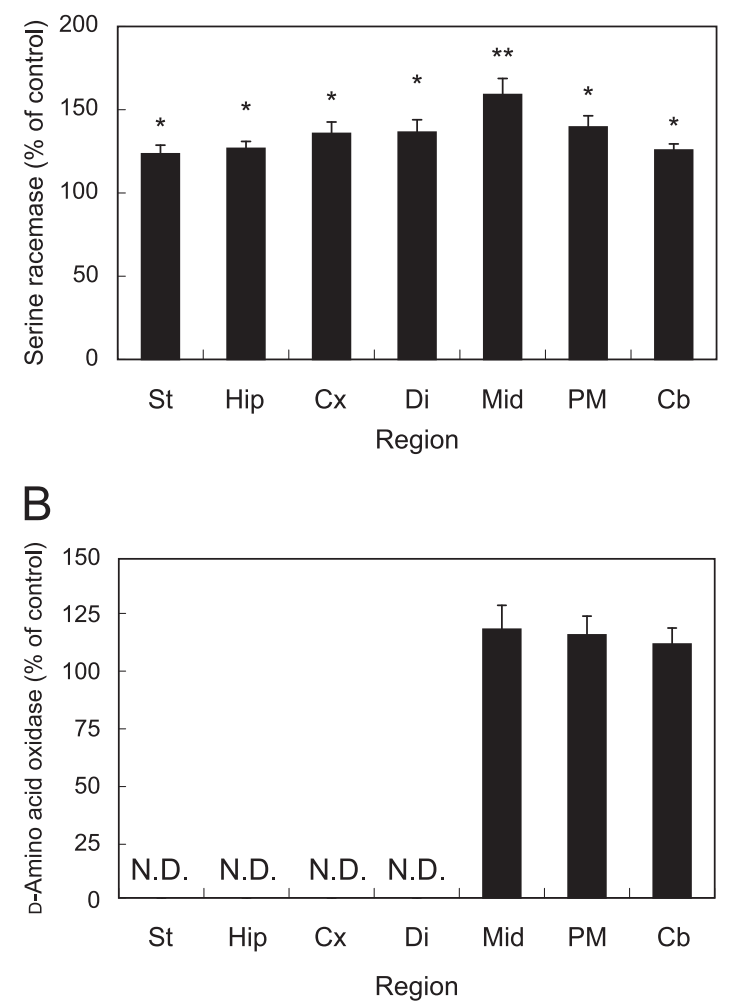

Fig. 3. Effect of chronic administration of morphine on the protein expressions of serine racemase (A) and D-amino acid oxidase (DAO) (B) in several brain areas of rats. Results are each the mean with S.E.M. of data obtained from six rats. A: The protein expression of serine racemase is expressed as means of the percentage of the salinetreated group (control). B: The protein expression of DAO is expressed as means of the percentage of the saline-treated group (control). ${ }^{*} P<0.05,{ }^{*} P<0.01$, as compared with the saline-treated group by the Mann-Whitney test. St, striatum; Hip, hippocampus; $\mathrm{Cx}$, cortex; $\mathrm{Di}$, diencephalon; Mid, midbrain; $\mathrm{PM}$, pons-medulla; $\mathrm{Cb}$, cerebellum.

\section{Discussion}

The present study demonstrated that long-term morphine administration for 30 days produced a significant augmentation of the mRNA and protein expressions of serine racemase and of D-serine levels in the rat brain. The regional distribution of both the mRNA and protein expressions of serine racemase and DAO in the salinetreated rats is in good agreement with those of serine racemase immunoreactivity and DAO activity $(2,5,8)$. The distributional pattern of D-serine contents in the saline-treated rats also coincides well with those of Dserine and serine racemase immunoreactivity $(2,5)$.

A moderate enhancement in the amount of serine racemase mRNA was seen in most parts of the brain following the treatment. Because morphine induces c-fos and junB and enhances activator protein-1 (AP-1)
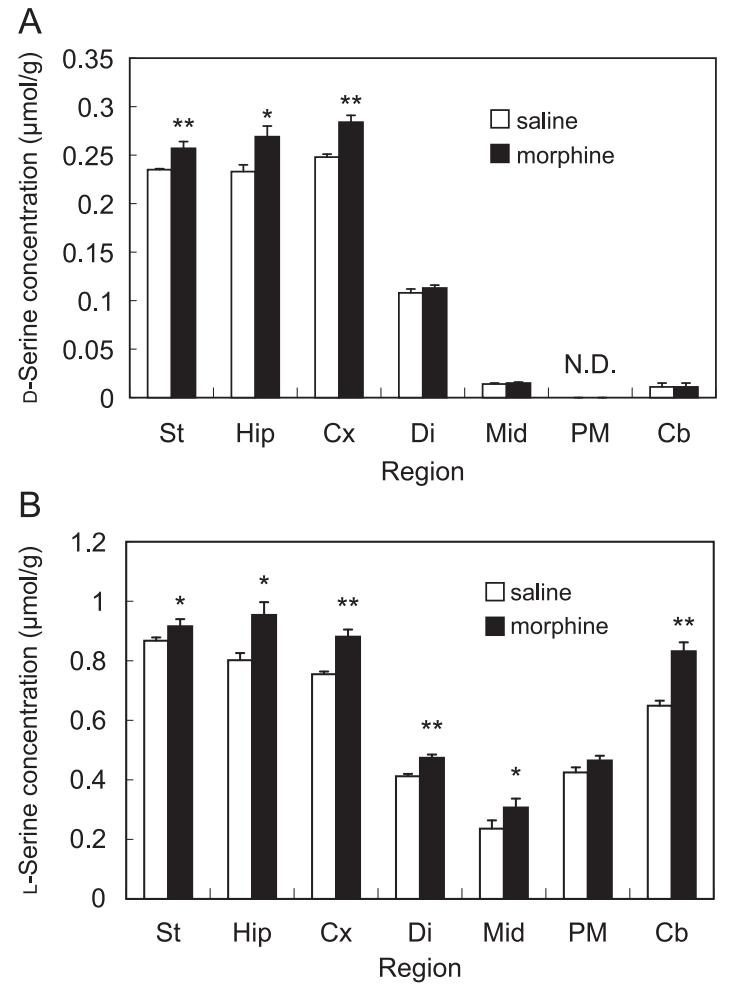

Fig. 4. Effect of chronic administration of morphine on the levels of D-serine (A) and L-serine (B) in several brain areas of rats. Results are each the mean with S.E.M. of data obtained from six rats. ${ }^{*} P<0.05,{ }^{*} P<0.01$, as compared with the saline-treated group by the Mann-Whitney test. St, striatum; Hip, hippocampus; Cx, cortex; Di, diencephalon; Mid, midbrain; PM, pons-medulla; $\mathrm{Cb}$, cerebellum.

binding in the striatum, nucleus accumbens, cortex, hippocampus, and thalamus $(22-25)$ and because rat serine racemase has some AP-1 binding elements in the first intron of the gene (26), the upregulation of serine racemase mRNA by chronic morphine could be due to the elevation in the AP-1-dependent transcriptional activation. Further support for this possibility comes from the fact that the gene expression of serine racemase has been induced by inflammatory stimuli in an AP-1dependent manner (26).

A moderate augmentation of both the mRNA and protein expressions of serine racemase and no change in the protein expression of DAO following the long-term morphine exposure may contribute to the elevation of the D-serine level in the brain. The elevated L-serine in several brain areas may also enhance the formation of $\mathrm{D}$ serine from L-serine by serine racemase. These findings correspond well with the fact that chronic administration of NMDA receptor antagonist MK-801 produces an enhancement of the D-serine levels in the forebrain (27). The slight augmentation of D-serine levels in the forebrain might be due to the $\alpha, \beta$-elimination of endogenous D- and L-serine by elevated serine racemase 
$(28-30)$. In fact, serine racemase not only racemizes Lserine but it also converts D- and L-serine into pyruvate via its $\alpha, \beta$-elimination activity $(28-30)$. Because the glycine site is not saturated by endogenous ligands under normal conditions $(31,32)$, the elevated D-serine levels in the forebrain might participate in the activation of NMDA receptor via the glycine site. More research is needed to elucidate whether an increase in the D-serine levels affects the extent of NMDA receptor activation. A slight elevation in the L-serine concentration was observed in almost all brain areas following the administration. Because D-3-phosphoglycerate dehydrogenase is known to be the first committed enzyme of L-serine biosynthesis in the phosphorylated pathway (33), an induction of D-3-phosphoglycerate dehydrogenase might occur after the chronic morphine treatment. In fact, stimulation such as crush injury has been shown to produce an up-regulation of D-3-phosphoglycerate dehydrogenase (34).

In light of the fact that DAO is predominantly concentrated in the hindbrain (Fig. 2B) $(2,8,9)$, the present findings provide further support for the view that serine racemase synthesizes D-serine from L-serine in the brain and that DAO metabolizes endogenous and/or newly synthesized D-serine in the hindbrain such as the cerebellum and pons-medulla. Several other findings strongly support this possibility: a) the intracerebroventricular application of L-serine produced a gradual and moderate enhancement in the D-serine concentrations in the forebrain, whereas a slight increase in Dserine occurred in the cerebellum and pons-medulla (35); b) D-serine administration caused a prolonged elevation of the D-serine levels in the forebrain, whereas a rapid decline in the enhanced D-serine levels was found in the cerebellum and pons-medulla (36); and c) the levels of D-serine in the cerebellum and rostral brain areas of mutant mice lacking DAO activity are higher than those of normal mice (37).

In contrast to serine racemase, the chronic morphine administration produced a significant increase in the mRNA expression of DAO in the forebrain but not the hindbrain, such as the diencephalon, midbrain, ponsmedulla, and cerebellum (Fig. 1B), although a transient elevation in the mRNA expression of DAO was seen in all the brain areas $4 \mathrm{~h}$ after acute morphine treatment $(20 \mathrm{mg} / \mathrm{kg})(15)$. Although the reason there were no changes in the mRNA expression of DAO in the hindbrain after the chronic treatment remains to be determined, it is likely that the morphine-induced augmentation in the mRNA expression of DAO could gradually be attenuated in the course of the repeated morphine administration. Alternatively, like the transient nature of the mRNA expression of DAO after the acute morphine administration (15), the enhanced expression of DAO mRNA could immediately return to control levels after the final morphine treatment.

A slight but significant elevation in the mRNA expression of DAO following the chronic administration might enhance the DAO activity in the forebrain. It is, however, unlikely because the protein expression of DAO was not detected in the forebrain after both the saline and morphine administration (Figs. 2B and 3B) and because histochemical studies have also shown that the activities of DAO are absent in the forebrain regions $(2,8)$. Further studies are needed to clarify the gene expression difference between the two enzymes after the chronic morphine administration.

A significant elevation of D-serine contents was observed in the forebrain following the chronic administration. Because D-serine is a full and obligatory agonist at the glycine sites of the NMDA receptors in the brain $(3,38)$ and because the chronic morphine administration lead to the activation of the NMDA receptors $(16-19)$, the enhanced D-serine levels in the forebrain could at least in part contribute to the activation of NMDA receptor via the glycine site.

\section{Acknowledgments}

This study was supported in part by grant from the Ministry of Education, Culture, Sports, Science, and Technology of Japan.

\section{References}

1 Hashimoto A, Nishikawa T, Oka T, Takahashi K. Endogenous D-serine in rat brain: N-methyl-D-aspartate receptor-related distribution and aging. J Neurochem. 1993;60:783-786.

2 Schell MJ, Molliver ME, Snyder SH. D-serine, an endogenous synaptic modulator: localization to astrocytes and glutamatestimulated release. Proc Natl Acad Sci U S A. 1995;92:39483952.

3 Hashimoto A, Oka T. Free D-aspartate and D-serine in the mammalian brain and periphery. Prog Neurobiol. 1997;52:325353.

4 Hashimoto A, Oka T, Nishikawa T. Extracellular concentration of endogenous free D-serine in the rat brain as revealed by in vivo microdialysis. Neuroscience. 1995;66:635-643.

5 Wolosker H, Blackshaw S, Snyder SH. Serine racemase: a glial enzyme synthesizing D-serine to regulate glutamate-N-methylD-aspartate neurotransmission. Proc Natl Acad Sci US A. 1999;96:13409-13414.

6 Konno R. Rat cerebral serine racemase: amino acid deletion and truncation at carboxy terminus. Neurosci Lett. 2003;349:111114.

7 Yoshikawa M, Kobayashi T, Oka T, Kawaguchi M, Hashimoto A. Distribution and MK-801-induced expression of serine racemase mRNA in rat brain by real-time quantitative PCR. 
Brain Res Mol Brain Res. 2004;128:90-94.

8 Horiike K, Tojo H, Arai R, Nozaki M, Maeda T. D-amino-acid oxidase is confined to the lower brain stem and cerebellum in rat brain: regional differentiation of astrocytes. Brain Res. 1994; 652:297-303.

9 Yoshikawa M, Oka T, Kawaguchi M, Hashimoto A. MK-801 upregulates the expression of d-amino acid oxidase mRNA in rat brain. Brain Res Mol Brain Res. 2004;131:141-144.

10 Mao J. NMDA and opioid receptors: their interactions in antinociception, tolerance and neuroplasticity. Brain Res Brain Res Rev. 1999;30:289-304.

11 Zhu H, Brodsky M, Gorman AL, Inturrisi CE. Region-specific changes in NMDA receptor mRNA induced by chronic morphine treatment are prevented by the co-administration of the competitive NMDA receptor antagonist LY274614. Brain Res Mol Brain Res. 2003;114:154-162.

12 Zhu H, Jang CG, Ma T, Oh S, Rockhold RW, Ho IK. Region specific expression of NMDA receptor NR1 subunit mRNA in hypothalamus and pons following chronic morphine treatment. Eur J Pharmacol. 1999;365:47-54.

13 Bajo M, Crawford EF, Roberto M, Madamba SG, Siggins GR. Chronic morphine treatment alters expression of N-methyl-Daspartate receptor subunits in the extended amygdala. J Neurosci Res. 2006;83:532-537.

14 Ozawa T, Nakagawa T, Shige K, Minami M, Satoh M. Changes in the expression of glial glutamate transporters in the rat brain accompanied with morphine dependence and naloxoneprecipitated withdrawal. Brain Res. 2001;905:254-258.

15 Yoshikawa M, Andoh H, Ito K, Suzuki T, Kawaguchi M, Kobayashi $\mathrm{H}$, et al. Acute treatment with morphine augments the expression of serine racemase and d-amino acid oxidase mRNAs in rat brain. Eur J Pharmacol. 2005;525:94-97.

16 Marek P, Ben-Eliyahu S, Gold M, Liebeskind JC. Excitatory amino acid antagonists (kynurenic acid and MK-801) attenuate the development of morphine tolerance in the rat. Brain Res. 1991;547:77-81.

17 Trujillo KA, Akil H. Inhibition of morphine tolerance and dependence by the NMDA receptor antagonist MK-801. Science. 1991;251:85-87.

18 Elliott K, Minami N, Kolesnikov YA, Pasternak GW, Inturrisi CE. The NMDA receptor antagonists, LY274614 and MK-801, and the nitric oxide synthase inhibitor, NG-nitro-L-arginine, attenuate analgesic tolerance to the mu-opioid morphine but not to kappa opioids. Pain. 1994;56:69-75.

19 Kolesnikov Y, Pasternak GW. Topical opioids in mice: analgesia and reversal of tolerance by a topical N-methyl-D-aspartate antagonist. J Pharmacol Exp Ther. 1999;290:247-252.

20 Martin G, Guadano-Ferraz A, Morte B, Ahmed S, Koob GF, De Lecea L, et al. Chronic morphine treatment alters N-methyl-Daspartate receptors in freshly isolated neurons from nucleus accumbens. J Pharmacol Exp Ther. 2004;311:265-273.

21 Martin G, Przewlocki R, Siggins GR. Chronic morphine treatment selectively augments metabotropic glutamate receptorinduced inhibition of N-methyl-D-aspartate receptor-mediated neurotransmission in nucleus accumbens. J Pharmacol Exp Ther. 1999;288:30-35.

22 Liu J, Nickolenko J, Sharp FR. Morphine induces c-fos and junB in striatum and nucleus accumbens via D1 and N-methyl-Daspartate receptors. Proc Natl Acad Sci U S A. 1994;91:8537-
8541.

23 Erdtmann-Vourliotis M, Mayer P, Riechert U, Grecksch G, Hollt $\mathrm{V}$. Identification of brain regions that are markedly activated by morphine in tolerant but not in naive rats. Brain Res Mol Brain Res. 1998;61:51-61.

24 Nye HE, Nestler EJ. Induction of chronic Fos-related antigens in rat brain by chronic morphine administration. Mol Pharmacol. 1996;49:636-645.

25 Frankel PS, Harlan RE, Garcia MM. Chronic administration of morphine alters immediate-early gene expression in the forebrain of post-dependent rats. Brain Res. 1999;835:204-212.

$26 \mathrm{Wu} \mathrm{S}$, Barger SW. Induction of Serine Racemase by Inflammatory Stimuli Is Dependent on AP-1. Ann N Y Acad Sci. 2004;1035:133-146.

27 Hashimoto A, Yoshikawa M, Andoh H, Yano H, Matsumoto H, Kawaguchi M, et al. Effects of MK-801 on the expression of serine racemase and d-amino acid oxidase mRNAs and on the d-serine levels in rat brain. Eur J Pharmacol. 2007;555:17-22.

28 De Miranda J, Panizzutti R, Foltyn VN, Wolosker H. Cofactors of serine racemase that physiologically stimulate the synthesis of the N-methyl-D-aspartate (NMDA) receptor coagonist D-serine. Proc Natl Acad Sci U S A. 2002;99:14542-14547.

29 Foltyn VN, Bendikov I, De Miranda J, Panizzutti R, Dumin E, Shleper M, et al. Serine racemase modulates intracellular Dserine levels through an alpha,beta-elimination activity. J Biol Chem. 2005;280:1754-1763.

30 Strisovsky K, Jiraskova J, Barinka C, Majer P, Rojas C, Slusher $\mathrm{BS}$, et al. Mouse brain serine racemase catalyzes specific elimination of L-serine to pyruvate. FEBS Lett. 2003;535:44-48.

31 Contreras PC. D-Serine antagonized phencyclidine- and MK801-induced stereotyped behavior and ataxia. Neuropharmacology. 1990;291-293.

32 Tanii Y, Nishikawa T, Hashimoto A, Takahashi K. Stereoselective antagonism by enantiomers of alanine and serine of phencyclidine-induced hyperactivity, stereotypy and ataxia in the rat. J Pharmacol Exp Ther. 1994;269:1040-1048.

33 Snell K. Enzymes of serine metabolism in normal, developing and neoplastic rat tissues. Adv Enzyme Regul. 1984;22:325400.

34 Yamashita N, Sakai K, Furuya S, Watanabe M. Selective expression of L-serine synthetic enzyme 3PGDH in Schwann cells, perineuronal glia, and endoneurial fibroblasts along rat sciatic nerves and its upregulation after crush injury. Arch Histol Cytol. 2003;66:429-436.

35 Hashimoto A. Effect of the intracerebroventricular and systemic administration of L-serine on the concentrations of D- and Lserine in several brain areas and periphery of rat. Brain Res. 2002;955:214-220.

36 Hashimoto A, Chiba Y. Effect of systemic administration of Dserine on the levels of D- and L-serine in several brain areas and periphery of rat. Eur J Pharmacol. 2004;495:153-158.

37 Hashimoto A, Nishikawa T, Konno R, Niwa A, Yasumura Y, Oka $\mathrm{T}$, et al. Free D-serine, D-aspartate and D-alanine in central nervous system and serum in mutant mice lacking D-amino acid oxidase. Neurosci Lett. 1993;152:33-36.

38 Matsui T, Sekiguchi M, Hashimoto A, Tomita U, Nishikawa T, Wada K. Functional comparison of D-serine and glycine in rodents: the effect on cloned NMDA receptors and the extracellular concentration. J Neurochem. 1995;65:454-458. 